\title{
Expression features of androgen receptor in special subtypes of breast cancer
}

\section{Guomin Xiang}

Tianjin Medical University Cancer Institute and Hospital

Jing Liu

Tianjin Medical University Cancer Institute and Hospital

Lu Cao

Tianjin Medical University Cancer Institute and Hospital

Cong Xu

Tianjin Medical University Cancer Institute and Hospital

Fang Liu

Tianjin Medical University Cancer Institute and Hospital

\section{Qingxiang Meng}

Tianjin Medical University Cancer Institute and Hospital

Danni Xu

Tianjin Medical University Cancer Institute and Hospital

Yun Niu ( $\nabla$ yunniu0823@126.com)

Tianjin Medical University Cancer Institute and Hospital https://orcid.org/0000-0001-5917-5604

\section{Research article}

Keywords: Special subtypes of breast cancer; androgen receptor; biomarker; target

Posted Date: June 20th, 2019

DOI: https://doi.org/10.21203/rs.2.10548/v1

License: (c) (i) This work is licensed under a Creative Commons Attribution 4.0 International License. Read Full License 


\section{Abstract}

Purpose The important role of the androgen receptor (AR) in invasive carcinoma of no specific type (NST) has been increasingly recognised. However, only a few studies have been reported in special subtypes of breast cancer. Thus, we aim to investigate the AR expression and its expression features in special subtypes of breast cancer. Methods This study collected clinicopathological data of 718 special subtypes of breast cancer from Tianjin Medical University Cancer Institute and Hospital. Immunohistochemical staining of AR and other biomarkers was performed. Results If the threshold of AR is $\geq 1 \%$, the positive rate of $A R$ in specific subtypes of breast cancer is $77.9 \%$ (559/718) of cases. Compared with the threshold of AR is $\geq 10 \%$, the positive percentage of AR in each subtype of breast cancer increases about $10 \%$. The positive expression rate of AR in carcinomas with apocrine differentiation is highest, and the coloration intensity is much stronger than that of other subtypes. The positive expression rate of AR is lowest in metaplastic carcinomas, almost negative; the positive expression rate of AR in invasive lobular carcinomas (ILCs), invasive micropapillary carcinomas (IMPCs), invasive papillary carcinomas (IPCs), and is mucinous carcinomas about $70.0 \%-80.0 \%$. Conclusions The expression features of AR in special subtypes of breast cancer vary in different subtypes, and to some extent, AR may be a useful biomarker for clinical diagnosis. Routine testing of AR has a certain guiding significance for clinical work. In addition, AR is expected to treat carcinomas with apocrine differentiation as a target.

\section{Background}

As the Cancer Statistics published by the magazine 'CA Cancer J Clin' in 2018[1], in the past year, there were about 8.6 million new cancer patients, including $24.2 \%$ breast cancer patients. There were 4.2 million women who died of cancer, of which breast cancer patients accounted for $15 \%$. From this point of view, breast cancer is the cancer with the highest incidence and mortality rate.

According to the 2012 World Health Organization (WHO) new classification criteria[2], the majority of the epithelial-derived breast tumours were classified as invasive carcinoma of no specific type (NST), and special subtypes of breast cancer account for a relatively low proportion. Special subtypes of breast cancer could be subdivided into invasive lobular carcinomas (ILCs), carcinomas with apocrine differentiation, mucinous carcinomas, metaplastic carcinomas, invasive papillary carcinomas (IPCs), invasive micropapillary carcinomas (IMPCs), carcinomas with medullary features and other invasive carcinomas. Compared with invasive carcinoma NST, special subtypes of breast cancer have variable morphological changes, different developmental rules and clinical features, and with varying prognosis.

There is overwhelming evidence from epidemiological studies that sex steroids (androgens, estrogens, progestogens) have an important role in the development of breast carcinomas. There molecular biomarkers are used in the routine clinical management of patients with invasive breast cancer: estrogen receptor (ER), progesterone receptor (PR) and human epidermal growth factor receptor 2 (HER2). Since all are targets and/or indicators of highly effective therapies against invasive breast cancer in various clinical settings. Staining for ER, PR and HER2 is becoming standard practice and increasingly, geneamplification studies for HER2 have also been incorporated into testing.

Growing evidence shows a strong and consistent link between bold concentrations of testosterone in postmenopausal women and risk of developing breast cancer[3]. It has been shown that androgen receptor (AR) is frequently expressed in some subtypes of breast carcinomas, including apocrine or lobular carcinomas, there is been increasing interest in the AR as a potential prognostic biomarker and treatment target[4-6]. A patient with metastatic TNBC who was $100 \%$ positive for AR was still in advanced condition after 6 different cytotoxic chemotherapy regimens, but was not effectively controlled, but treated with the AR inhibitor bicalutamide after the 4 month, the patient was response to the AR inhibitor bicalutamide and remained tumour-free for 12 months[7], indicating the therapeutic significance of AR in AR-positive breast cancer. So far, there are a lot of studies on the expression and clinical significance of AR in invasive carcinoma NST at home and abroad[4, 6, 8-10], but there are quite few studies on the expression of AR in special subtypes of breast cancer. Therefore, this study aimed to investigate the clinicopathological data and immunohistochemical features of 718 patients with special subtypes of breast cancer, to explore the expression features of AR in different special subtypes of breast cancer.

\section{Methods}

\subsection{Study population}

Using the 2012 WHO criteria, a series of patients diagnosed with special subtypes of breast cancer $(n=718)$ between March 1, 2018 and December 31,2018 was retrieved from the files of the Department of Breast Cancer Pathology and Research Laboratory, Tianjin Medical University Cancer Institute and Hospital. The exclusion criteria were the following: patients with invasive carcinoma NST, bilateral breast cancer, multiple breast cancer, mixed breast cancer, nonepithelial breast malignancies, and those who received any type of neoadjuvant chemotherapy, metastatic disease at presentation, prior history of any type of malignant tumor, development of a second primary cancer, and incomplete information.

Patients with special subtypes of breast cancer ranged from 15 to 81 years old with a median age of 55 years. In addition, haematoxylin and eosin (HखE) slides were centrally reviewed by two senior pathologists, who were blinded to patients' clinicopathologic characteristics. Data on the status of the ER, PR, HER2, Ki-67, p53, CK5/6 and EGFR were based on a review of Immunohistochemical (IHC)-stained sections. The clinicopathological data of those who were included in the study was available. Patients were treated following the National Comprehensive Cancer Network (NCCN) breast cancer treatment guidelines.

\subsection{IHC analysis}

All of the selected samples were detected using IHC analysis for ER, PR, HER2, p53, Ki-67, CK5/6, EGFR and AR. IHC methods was performed as previously reported[11]. In detail, the samples (four-micrometer-thick sections) were fixed in 10\% neutral buffered formalin and then paraffin embedded. The sections were then deparaffinized in xylene and rehydrated in graded concentrations of ethyl alcohol. Antigen retrieval was performed in an autoclave for 2 min $30 \mathrm{~s}$ to 
enhance immunoreactivity. Endogenous peroxidase activity was blocked by incubating the tissue in $3 \%$ peroxidase-blocking solution for 10 min. Subsequently, the sections were blocked with normal goat serum for $30 \mathrm{~min}$ and incubated overnight at $4^{\circ} \mathrm{C}$ with primary antibodies. The sections were stained by primary antibodies with AR (clone AR441; Maixin), ER (clone SP1; Invitrogen), PR (clone SP2; Invitrogen), HER2 (clone CB11; Invitrogen), Ki-67 (clone SP6; Invitrogen), p53 (clone SP5; Invitrogen), CK5/6 (clone D5/16B4; Maixin) and EGFR (clone UMAB95; ZSGB), respectively. After washing with phosphate-buffered saline (PBS), the sections were incubated with biotin-labeled secondary antibody and streptavidin horseradish peroxidase according to the manufacturer's protocol. Visualization was performed with 3, 30-diaminobenzidine as the chromogen-substrate. The slices were then counterstained with haematoxylin. The positive controls of ER, PR and HER2 was the known external control, positive control of AR was the known positive prostate tissues. For negative controls, PBS was used instead of primary antibodies.

\subsection{Staining evaluation}

For each antibody, the location of immunoreactivity, percentage of stained cells, and intensity were determined. The results of many IHC studies provide strong support for defining "ER-positive" clinically as $\geq 1 \%$ positive-staining tumour cells regardless of intensity[12]. Clinically, AR is highly expressed in both normal and malignant breast tissue, with positive expression defined as $\mathrm{IHC}$ nuclear staining $\geq 1 \%$ or $\geq 10 \%$, depending on the study (Table 1 ), but the value of $A R$ positivity as a prognostic marker has not yet been defined. Herein, we applied the same approach for AR and considered at least one percent or ten nuclear staining of any intensity as positive AR assays. Generally, the coloration intensity of AR is much weaker than ER and PR. Therefore, the coloration intensity of $A R$ is defined as mild expression (light yellow), moderate expression (light brown yellow), and strong expression (brown yellow).

Tumours are defined as positive for HER2 if IHC was scored as 3+ and tumours with HER2 scored as 2+ were further confirmed Her2-gene amplification detected by in situ hybridization[13]. The cut-off point for $p 53$ positivity was set at $\geq 10 \%$ of tumour cells, with strong nuclear reactivity[14]. Ki-67 status was expressed in terms of percentage of positive cells, with a threshold of $20 \%$ of positive cells, with strong nuclear reactivity[15]. A cut-off value of $10 \%$ for CK5/6 (cytoplasm) was used[16, 17]. EGFR expression (membrane) was scored same as HER2 expression, and the scores of 0 and $1+$ were considered to be negative, and $2+$ and $3+$ were considered as positive[16, 17].

As previously described[15], IHC surrogates for molecular subtype classification are: luminal A subtype (ER and PR positive, HER2 negative and Ki-67 < $20 \%$ ), luminal B (HER2) subtype (ER positive, no or low PR expression, HER2 negative and Ki-67 $\geq 20 \%$ ), luminal B (HER2 ${ }^{+}$) subtype (ER positive, any PR expression, HER2 positive and any Ki-67 index), HER2-overexpressed (the absence of ER and PR expression, HER2 overexpression or gene amplification), TNBC (no expression of ER, PR and HER2).

\subsection{Statistical analysis}

Statistical analysis was carried out using SPSS 22.0 software (SPSS Inc., Chicago, IL, USA). Clinical data were described as a percentage. Differences of the categorical variables between groups were evaluated by the Chi-square test. $P$ values $<0.05$ were considered statistically significant.

\section{Results}

\subsection{Clinicopathological parameters}

The study cohort consisted of 718 female patients with special subtypes of breast cancer. The cancer types were as follows: IMPCs ( $n=160)$, mucinous carcinomas $(n=144)$, ILCs $(n=134)$, carcinomas with apocrine differentiation $(n=88)$, IPCs $(n=73)$, metaplastic carcinomas $(n=44)$, carcinoma with neuroendocrine features $(n=37)$, carcinoma with medullary features $(n=15)$, acinic cell carcinoma $(n=7)$, adenoid cystic carcinomas $(n=5)$, invasive cribriform carcinomas $(n=4)$, glycogen-rich clear cell carcinomas $(n=4)$ and secretory carcinomas $(n=3)$. Patient's characteristics are listed in Supplementary Table 1 .

\subsection{Positive rates and coloration intensity of AR in special subtypes of breast cancer}

AR is frequently expressed in breast cancer tissues. As shown in Figure 1, tumours with $\geq 10 \%$ nuclear-stained cells are considered to be positive for AR, the positive rate of AR in special subtypes of breast cancer is $68.1 \%$ (489/718) of total cases; The positive expression rate of AR in the carcinomas with apocrine differentiation is $95.5 \%$ (84/88) of cases; followed by the ILCs is $79.1 \%(106 / 134)$ of cases; the positive expression rate of AR in IMPCs, IPCs and mucinous carcinoma is $68.8 \%(110 / 160), 67.1 \%(49 / 73)$ and $66.7 \%(96 / 144)$ of cases, respectively; On the contrary, the positive rate of AR in metaplastic carcinomas is the lowest, only $11.4 \%$ (5/44) of cases. Interestingly, if the threshold of AR is $\geq 1 \%$, the positive rate of AR in specific subtypes of breast cancer is $77.9 \%$ $(559 / 718)$ of total cases, and the positive percentage of AR in each subtype of breast cancer is increased about $10 \%$.

Coloration intensity of AR in different pathological subtypes is shown in Table 2. The coloration intensity of AR is mainly mild and mild-to-moderate expression, there are quite a few cases presenting moderate and strong expression. On the contrary, the coloration intensity of AR in carcinoma with apocrine differentiation is mainly the moderate and strong expression cases. Perhaps this is one of the reasons why coloration intensity of AR is not included in the scored criteria of AR-positive. The AR immunostaining was predominantly localized in the nucleus of breast tumour cells, but in a few cases, the protein was localized in both the nucleus and cytoplasm. The negative (-), mild (+), morderate (++), and strong (+++) immunohistochemical expression of AR in specific subtypes of breast cancer are shown in Figure 2.

\subsection{The relationship between AR expression and clinicopathological parameters in specific subtypes of breast cancer}

The relationship between AR expression and clinicopathological factors in specific subtypes of breast cancer is summarized in Supplementary Table 2, if AR positivity was defined as any nuclear staining in tumor cells $\geq 10 \%$, the positive rates of AR in the ER-positive and PR-positive groups were $71.9 \%$ (387/538) 
and 74.5\% (342/459), respectively, which was higher than 56.7\% (102/180) and 56.8\% (147/259) in the ER-negative and PR-negative groups $(P<0.001, P<$ 0.001); AR positive expression rate was 73.9\% (99/134) in the HER2-positive group, compared with 66.8\% (390/584) of AR-positive cases in the HER2-negative group, the difference was not statistically significant $(P>0.05)$. Immunohistochemically, AR expression was the most prevalent in the HER2-positive subtype $(78.8 \%, 52 / 66)$, followed by the luminal B (HER2) subtype $(73.4 \%, 212 / 289)$, the luminal A subtype $(70.7 \%, 128 / 181)$ and the luminal B (HER2 $\left.{ }^{+}\right)$subtype $(69.1 \%, 47 / 68)$, the lowest rate was in TNBC (43.9\%, 50/114). In addition, the differences between AR expression and patient's age, Ki-67 index, CK5/6 and EGFR status were statistically significant $(P<0.05)$. If the cut-off value of $A R$ is $\geq 1 \%$, the difference between the clinicopathological parameters of $A R$ is similar to the AR-positive nuclear staining tumour cells $\geq 10 \%$ (except the difference between AR expression and patient's age is inconsistent).

\subsection{The difference of the expression characteristics of AR in different specific subtypes of breast cancer}

Most of the carcinomas with apocrine differentiation are ER-negative, only a few cases are ER-positive, but the positive expression rate was lower and coloration intensity of ER was weaker. The positive rate of EGFR was as high as 75.0\% (66/88), and 71.6\% (63/88) of cases was co-expressed with the AR, this is consistent with our previous research results[18]. Compared with other subtypes of carcinoma, the coloration intensity of AR is much stronger, and there were few cases of heterogeneous coloration. If the cut-off value of AR was $\geq 10 \%$, the difference between AR expression and the patient's age was statistically significant $(P=0.030)$; but if the cut-off value of AR was $\geq 1 \%$, there was no statistically significant between AR expression with different pathological parameters. Another ER-negative breast cancer-metaplastic carcinomas account for $0.2 \%-5.0 \%$ of all invasive breast cancers. In our study, the patients who were $\leq 50$ years old account for $40.9 \%(18 / 44)$ of cases. The EGFR-positive group is significantly higher than EGFR-negative group (88.6\%, $39 / 44$ vs $11.4 \%$, $5 / 44)$. The $\chi 2$ test found no significant difference between the AR expression and the patient's clinicopathological parameters $(P>0.05)$, regardless of the threshold of AR (Table 3).

In ILCs, if a positive AR status was defined as average of $\geq 1 \%$ positive tumor nuclei regardless of coloration intensity, AR expression was associated with lymph node status $(P=0.030)$, but if the threshold of AR is $\geq 10 \%$, there was no statistically significant between the AR expression and patient's clinicopathological parameters $(P>0.05)$. In mucinous carcinomas, compared with AR-negative group, the AR-positive group had a higher nuclear grade (83.3\%, 80/96 vs $52.1 \%, 25 / 48$ or $78.9 \%, 86 / 109$ vs $54.3 \%, 19 / 35 ; P<0.05)$, irrespective of nuclear coloration intensity of AR. Additionally, if the threshold of AR is $\geq 10 \%$, the AR expression was related to the PR status $(P=0.033)$, but if the cut-off value of AR was $\geq 1 \%$, there was no statistically significant between AR expression with different pathological parameters (Table 4).

In IPCs, the difference between the AR expression and the PR status and CK5/6 was statistically significant $(P<0.05)$, regardless of the threshold of AR. Moreover, if the threshold of AR was set as $\geq 1 \%$, there was a statistically significant between the AR and the ER status $(P=0.006)$. However, if the threshold of AR was set as $\geq 10 \%$, there was no statistically significant between the AR and the ER status $(P>0.05)$. In IMPCs, if the threshold of AR was set as $\geq 10 \%$, the AR expression was associated with the ER status $(P=0.014)$, the PR status $(P<0.001)$ and the EGFR status $(P=0.043)$. However, if the threshold of AR was set as $\geq 1 \%$, the AR status was only related to the ER status $(P=0.013)$ (Table 5$)$. A representative representation of a typical subtype of breast cancer is shown in Figure 3.

\section{Discussion}

As can be seen in the new WHO classification of breast cancer in 2012, the most common clinically is invasive carcinoma NST, and special subtypes of breast cancer are relatively rare in clinical practice[2]. This article only includes several common special subtypes into the analysis. The main reason is that there are quite few cases of special subtypes of breast cancer in a short period of time, which is not statistically significant. Because this study collected cases from March 1, 2018 to December 31, 2018, lacking of follow-up data, the focus of this study is on the expression characteristics of AR in specific subtypes of breast cancer. Therefore, a multicenter clinical study was needed to further validate the prognostic significance of AR in specific subtypes of breast cancer.

It has been clearly pointed out that ER is an independent prognostic factor for breast cancer, and anti-estrogen therapy is a first-line endocrine therapy for patients with ER-positive breast cancer. However, about 30\% of ER-positive breast cancer patients are resistant to anti-estrogen therapy[19] and ER-negative breast cancer patients are not effective against anti-estrogen therapy. Therefore, it is urgent to find a new method of endocrine therapy. In postmenopausal women, the estrogen level decreases to the same level as that in men, while the androgen level is not affected. Ogawa et al[14]. revealed that most cases of breast cancer with high AR expression were in postmenopausal patients. Due to loss of ovarian function, estrogen is mainly converted from androgen. Therefore, the androgen-AR response for breast cancer would be more significant in postmenopausal women.

In carcinomas with apocrine differentiation, AR is almost $100 \%$ positive, which is related to the origin of the mammary gland. The mammary gland that is a modified apocrine gland shares the same embryological origin with salivary and sweat glands. The apocrine epithelium is influenced by androgens and is an active site for androgen metabolism[20]. Staining for ER and PR is usually negative, but AR has been shown to be frequently over-expressed[4, 21]. Although ER-negative, cancer characterized by apocrine differentiation is similar to luminal breast cancer, the possible mechanism is that AR plays a role in carcinomas with apocrine differentiation by mimicking ER[22]. Given that AR expression is a defining feature of carcinoma with apocrine differentiation, it is feasible that AR may, at least in part, contribute to poor prognosis in this subtype[23]. This concept is supported by in vitro studies demonstrate that AR signalling promotes proliferation of cell models in carcinoma with apocrine differentiation and is inhibited by AR antagonist or AR silencing[24]. The androgen signalling associated with these tumours may lead to the development with of new therapeutic modalities for these tumours in the future.

Immunohistochemical analysis of metaplastic carcinomas has revealed that $>90 \%$ of these cancers are negative for ER, PR and HER2, while a small number of cases are positive for ER, and the percentage of ER-positive is $<20 \%$, the coloration intensity of ER-positive is almost weak[25]. This study found that the positive expression rate of another hormone receptor-AR in metaplastic carcinoma is extremely low, and the percentage of AR-positive cases is also lower $(<20 \%)$, and the coloration intensity is mild. Consistent with Park et al[26]., AR may be a new diagnostic factor in metastatic cancer for future diagnostic 
analysis. According to the biological activity of AR in metaplastic carcinoma, these carcinomas can be further classified as quadruple negative disease (no expression of ER, PR, AR and HER2).

Clinically, the incidence of ILC has increased relative to that of invasive carcinoma NST, ILC is the second most common subtype of breast cancer. Consistent with previous studies[26-28], the positive expression rate of AR in ILC is quite high. Irrespective of whether a $1 \%$ or $10 \%$ criterion was used, the positive rate of AR in ILC is as high as $80 \%$. In addition, this study found that the positive expression rate of AR in ILC is secondly to its positive expression rate in carcinomas with apocrine differentiation. To some extent, it needs further study to verify that AR may be related to the poor prognosis of ILC.

Typically, mucinous carcinoma is positive for ER and PR, while AR is expressed at a low level[26, 29]. In this study, the positive rate of AR in mucinous carcinoma is about $70 \%$, regardless of the cut-off value of AR. Similarly, previous study reported mucinous carcinoma exhibiting a relatively high frequency of positivity for AR[28, 30]. The prevalence varies to such an extent, given that: 1) the expression intensity of AR is mild, the different criteria adopted by different pathologists; 2) the AR antibodies used in studies are different; 3) the different sample sources, sample sizes and different statistical method. In addition, compared with AR-negative cases, AR-positive cases have a higher nuclear fraction, more commonly in hypercellular mucinous carcinoma, while AR-negative expression is more common in pure type mucinous carcinoma, with lower nuclear grade. Clinically, mucinous carcinoma is generally considered to have a good prognosis and associated with low rates of local and distant recurrence. However, it has been proven that mucinous carcinomas with the intermediate and/or high nuclear grade are prone to have a far worse prognosis and higher incidence of lymph node metastasis. We speculate that this may be related to the presence of AR.

In conclusion, irrespective of whether a $1 \%$ or $10 \%$ criterion was used, the expression of AR varies in different pathological subtypes of breast cancer, and to some extent, AR may be a useful biomarker for clinical diagnosis. In addition, AR is expressed in a significant number of carcinomas with apocrine differentiation, which indicates that the assessment of AR expression may lead to new treatment strategies for carcinomas with apocrine differentiation.

\section{Declarations}

Compliance with Ethical Standards: This study was reviewed and approved by the Institutional Ethic Committee of Tianjin Medical University Instituted and Cancer Hospital and has been performed in consistent with the 1964 Helsinki declaration and its later amendments or comparable ethical standards.

Funding: This study was funded by the Tianjin Municipal Science and the Technology Commission Research Fund (grant number: 15JCYBJC27800).

Conflict of interest: The authors declare that they have no conflict of interest.

Informed consent: Informed consent was obtained from all the patients before their surgery and the examination of the specimens.

Author contributions: Yun Niu contributed to design the study and re-evaluate the cases; Guomin Xiang contributed significantly to analysis the results and wrote the manuscript; Jing Liu and Lu Cao performed the data analyses and provided writing assistance; Cong Xu and Fang Liu helped performed the analysis with constructive discussions; Qingxiang Meng and Danni Xu helped performed the analysis with constructive discussions. All authors read and approved the final manuscript.

\section{References}

1. Bray F, Ferlay J, Soerjomataram I, Siegel RL, Torre LA, Jemal A. Global cancer statistics 2018: GLOBOCAN estimates of incidence and mortality worldwide for 36 cancers in 185 countries. CA Cancer J Clin 2018; 68(6):394-424.

2. Lakhani SR, Ellis IO, Schnitt SJ, et al. WHO classification of tumours of the breast. IARC Press, Lyon, 2012;8-236.

3. Lonning PE, Eikesdal HP. Aromatase inhibition 2013: clinical state of the art and questions that remain to be solved. Endocr Relat Cancer 2013; 20(4):R183-201.

4. Secreto G, Girombelli A, Krogh V. Androgen excess in breast cancer development: implications for prevention and treatment. Endocr Relat Cancer 2018.

5. Giovannelli P, Di Donato M, Galasso G, Di Zazzo E, Bilancio A, Migliaccio A. The Androgen Receptor in Breast Cancer. Front Endocrinol (Lausanne) 2018; 9:492.

6. Vasiliou SK, Diamandis EP. Androgen receptor. A promising therapeutic target in breast cancer. Crit Rev Clin Lab Sci 2019; 56(3):200-223.

7. Arce-Salinas C, Riesco-Martinez MC, Hanna W, Bedard P, Warner E. Complete Response of Metastatic Androgen Receptor-Positive Breast Cancer to Bicalutamide: Case Report and Review of the Literature. J Clin Oncol 2016; 34:e21-24.

8. Venema CM, Bense RD, Steenbruggen TG, Nienhuis HH, Qiu SQ, van Kruchten M, Brown M, Tamimi RM, Hospers GAP, Schroder CP et al. Consideration of breast cancer subtype in targeting the androgen receptor. Pharmacol Ther 2019.

9. Cao L, Xu C, Xiang G, Liu F, Liu X, Li C, Liu J, Meng Q, Jiao J, Niu Y. AR-PDEF pathway promotes tumour proliferation and upregulates MYC-mediated gene transcription by promoting MAD1 degradation in ER-negative breast cancer. Mol Cancer 2018; 17(1).

10. Liu X, Feng C, Liu J, Cao L, Xiang G, Liu F, Wang S, Jiao J, Niu Y. Androgen receptor and heat shock protein 27 co-regulate the malignant potential of molecular apocrine breast cancer. J Exp Clin Cancer Res 2018; 37(1):90.

11. Xiang G, Liu F, Liu J, Meng Q, Li N, Niu Y. Prognostic role of Amphiregulin and the correlation with androgen receptor in invasive breast cancer. Pathol Res Pract 2019.

12. Reisenbichler ES, Lester SC, Richardson AL, Dillon DA, Ly A, Brock JE. Interobserver concordance in implementing the 2010 ASCO/CAP recommendations for reporting ER in breast carcinomas: a demonstration of the difficulties of consistently reporting low levels of ER expression by manual quantification.

Page 5/11 
Am J Clin Pathol 2013; 140(4):487-494.

13. Pennacchia I, Carbone A, Di Cerbo A, Vecchio FM, Arena V. 2013 ASCO/CAP updated guidelines for human epidermal growth factor receptor 2 testing: Impact on routine practice. Breast 2015; 24(3):285-286.

14. Ogawa Y, Hai E, Matsumoto K, Ikeda K, Tokunaga S, Nagahara H, Sakurai K, Inoue T, Nishiguchi Y. Androgen receptor expression in breast cancer. relationship with clinicopathological factors and biomarkers. Int J Clin Oncol 2008; 13(5):431-435.

15. Goldhirsch A, Winer EP, Coates AS, Gelber RD, Piccart-Gebhart M, Thurlimann B, Senn HJ, Panel members. Personalizing the treatment of women with early breast cancer: highlights of the St Gallen International Expert Consensus on the Primary Therapy of Early Breast Cancer 2013. Ann Oncol 2013; 24(9):2206-2223.

16. Handa T, Katayama A, Yokobori T, Yamane A, Horiguchi J, Kawabata-Iwakawa R, Rokudai S, Bao P, Gombodorj N, Altan B et al. Caspase14 expression is associated with triple negative phenotypes and cancer stem cell marker expression in breast cancer patients. J Surg Onco/ 2017; 116(6):706-715.

17. Obayashi S, Horiguchi J, Higuchi T, Katayama A, Handa T, Altan B, Bai T, Bao P, Bao H, Yokobori T et al. Stathmin1 expression is associated with aggressive phenotypes and cancer stem cell marker expression in breast cancer patients. Int J Oncol 2017; 51(3):781-790.

18. Liu X, Feng C, Liu J, Liu J, Li C, Xu C, Niu Y. The importance of EGFR as a biomarker in molecular apocrine breast cancer. Hum Pathol 2018; 77:1-10.

19. Chuffa LG, Lupi-Junior LA, Costa AB, Amorim JP, Seiva FR. The role of sex hormones and steroid receptors on female reproductive cancers. Steroids 2017; 118:93-108.

20. Javed A, Lteif A. Development of the human breast. Semin Plast Surg 2013; 27(1):5-12.

21. Gatalica Z. Immunohistochemical Analysis of Apocrine Breast Lesions. Pathol Res Pract 1997; 193(11-12):753-758.

22. Mills AM, E Gottlieb C, M Wendroth S, M Brenin C, Atkins KA. Pure Apocrine Carcinomas Represent a Clinicopathologically Distinct Androgen ReceptorPositive Subset of Triple-Negative Breast Cancers. Am J Surg Pathol 2016; 40:1109-16.

23. Tsang JY, Ni YB, Chan SK, Shao MM, Law BK, Tan PH, Tse GM. Androgen receptor expression shows distinctive significance in ER positive and negative breast cancers. Ann Surg Oncol 2014; 21(7):2218-2228.

24. Narayanan R, Dalton JT. Androgen Receptor: A Complex Therapeutic Target for Breast Cancer. Cancers 2016; 8(12).

25. Zhai J, Giannini G, Ewalt MD, Zhang EY, Invernizzi M, Niland J, Lai LL. Molecular characterization of metaplastic breast carcinoma via next generation sequencing. Hum pathol 2018.

26. Park S, Koo J, Park HS, Kim JH, Choi SY, Lee JH, Park BW, Lee KS. Expression of androgen receptors in primary breast cancer. Ann Onco/ 2010; 21(3):488492.

27. Riva C, Dainese E, Caprara G, Rocca PC, Massarelli G, Tot T, Capella C, Eusebi V. Immunohistochemical study of androgen receptors in breast carcinoma. Evidence of their frequent expression in lobular carcinoma. Virchows Arch 2005; 447(4):695-700.

28. Qi JP, Yang YL, Zhu H, Wang J, Jia Y, Liu N, Song YJ, Zan LK, Zhang X, Zhou M et al. Expression of the androgen receptor and its correlation with molecular subtypes in 980 chinese breast cancer patients. Breast Cancer (Auckl) 2012; 6:1-8.

29. Cho LC, Hsu YH. Expression of androgen, estrogen and progesterone receptors in mucinous carcinoma of the breast. Kaohsiung J Med Sci 2008; 24:227232.

30. Honma N, Sakamoto G, Akiyama F, Esaki Y, Sawabe M, Arai T, Hosoi T, Harada N, Younes M, Takubo K. Breast carcinoma in women over the age of 85: distinct histological pattem and androgen, oestrogen, and progesterone receptor status. Histopathology 2003; 42:120-127.

\section{Tables}

Table 1. Various studies on the frequency of AR positivity among breast cancer

\begin{tabular}{lllll} 
Reference & Number of cases & Number of AR+ & AR positivity definition & AR antibody \\
\hline Moinfar et al[1]. 2003 & 145 invasive carcinomas & $87(60.0 \%)$ & $\geq 10 \%$ & AR 441 (Dako) \\
\hline Agoff et al[2].2003 & 88 invasive carcinomas & $51(58.0 \%)$ & $\geq 5 \%$ & F39.4.1 Biogenex \\
\hline Gonzalez et al[3]. 2008 & 111 primary invasive ductal carcinomas & $83(74.8 \%)$ & $\geq 1 \%$ & AR 441 (Dako) \\
\hline Ogawa et al[4].2008 & 227 invasive carcinomas & $142(62.6 \%)$ & $\geq 10 \%$ & AR441 (Dako) \\
\hline Park et al[5].2010 & 347 invasive carcinomas & $253(72.9 \%)$ & $\geq 10 \%$ & AR 441 (Dako) \\
\hline Yu et al[6]. 2011 & 327 invasive ductal breast carcinomas & $237(72.5 \%)$ & $\geq 10 \%$ & Anti-AR Biocare \\
\hline Peters et al[7]. 2012 & 73 primary breast tumours & $41(56.0 \%)$ & $\geq 1 \%$ & Medical \\
\hline Safarpour et al[8].2014 & 400 invasive breast cancers & & AR 441 (Dako) \\
\hline Grogg A et al[9].2015 & 353 primary breast cancers & $351(87.8 \%)$ & $\geq 1 \%$ & AR 441 (Dako) \\
\hline Elebro et al[10].2017 & 671 invasive breast cancers & $307(87.0 \%)$ & $\geq 1 \%$ & AR441(Thermo Scientific) \\
\hline Kensler et al[11].2018 & 4147 invasive breast cancers & $573(85.4 \%)$ & $\geq 10 \%$ & AR 441 (Dako)
\end{tabular}

Page 6/11 
References

1. Moinfar F, Okcu M, Tsybrovskyy O, Regitnig P, Lax SF, Weybora W, Ratschek M, Tavassoli FA, Denk H. Androgen receptors frequently are expressed in breast carcinomas: potential relevance to new therapeutic strategies. Cancer 2003; 98(4):703-711.

2. Agoff SN, Swanson PE, Linden H, Hawes SE, Lawton TJ. Androgen receptor expression in estrogen receptor-negative breast cancer. Immunohistochemical, clinical, and prognostic associations. Am J Clin Pathol 2003; 120: 725-731.

3. Gonzalez LO, Corte MD, Vazquez J, Junquera S, Sanchez R, Alvarez AC, Rodriguez JC, Lamelas ML, Vizoso FJ. Androgen receptor expresion in breast cancer: relationship with clinicopathological characteristics of the tumors, prognosis, and expression of metalloproteases and their inhibitors. $B M C$ cancer 2008; 8:149.

4. Ogawa Y, Hai E, Matsumoto K, Ikeda K, Tokunaga S, Nagahara H, Sakurai K, Inoue T, Nishiguchi Y. Androgen receptor expression in breast cancer: relationship with clinicopathological factors and biomarkers. Int J Clin Oncol 2008ه13(5):431-435.

5. Park S, Koo J, Park HS, Kim JH, Choi SY, Lee JH, Park BW, Lee KS. Expression of androgen receptors in primary breast cancer. Ann Oncol 2010; 21(3):488492.

6. Yu Q, Niu Y, Liu N, Zhang JZ, Liu TJ, Zhang RJ, Wang SL, Ding XM, Xiao XQ. Expression of androgen receptor in breast cancer and its significance as a prognostic factor. Ann Oncol 2011; 22(6):1288-1294.

7. Peters KM, Edwards SL, Nair SS, French JD, Bailey PJ, Salkield K, Stein S, Wagner S, Francis GD, Clark SJ, Brown MA. Androgen receptor expression predicts breast cancer survival: the role of genetic and epigenetic events. BMC Cancer, 2012; 12:132.

8. Safarpour D, Pakneshan S, Tavassoli FA. Androgen receptor (AR) expression in $\mathbf{4 0 0}$ breast carcinomas: is routine AR assessment justified? Am J Cancer Res. 2014; 16:4:353-68.

9. Grogg A, Trippel M, Pfaltz K, Ladrach C, Droeser RA, Cihoric N, Salhia B, Zweifel M, Tapia C. Androgen receptor status is highly conserved during tumor progression of breast cancer. BMC cancer 2015; 15:872.

10. Elebro K, BendahI PO, Jernstrom H, Borgquist S. Androgen receptor expression and breast cancer mortality in a population-based prospective cohort Breast Cancer Res Treat 2017; 165(3):645-657.

11. Kensler KH, Poole EM, Heng YJ, Collins LC, Glass B, Beck AH, Hazra A, Rosner BA, Eliassen AH, Hankinson SE et al. Androgen Receptor Expression and Breast Cancer Survival: Results From the Nurses' Health Studies. J Natl Cancer Inst 2018.

Table 2. Coloration intensity of AR in different pathological types

\begin{tabular}{|c|c|c|c|c|c|c|c|c|}
\hline $\begin{array}{l}\text { Pathological } \\
\text { types } \\
\text { Coloration } \\
\text { intensity of AR }\end{array}$ & $\begin{array}{l}\text { Total } \\
\text { cases } \\
\text { No.(\%) }\end{array}$ & $\begin{array}{l}\text { Carcinomas with apocrine } \\
\text { differentiation No.(\%) }\end{array}$ & $\begin{array}{l}\text { Metaplastic } \\
\text { carcinomas } \\
\text { No.(\%) }\end{array}$ & $\begin{array}{l}\text { ILCs } \\
\text { No.(\%) }\end{array}$ & $\begin{array}{l}\text { Mucinous } \\
\text { carcinomas No. } \\
(\%)\end{array}$ & $\begin{array}{l}\text { IPCs } \\
\text { No.(\%) }\end{array}$ & $\begin{array}{l}\text { IMPCs } \\
\text { No.(\%) }\end{array}$ & $\begin{array}{l}\text { Others } \\
\text { No.(\%) }\end{array}$ \\
\hline Total & 718 & 88 & 44 & 134 & 144 & 73 & 160 & 75 \\
\hline Neg & $159(22.2)$ & $3(3.4)$ & $34(77.3)$ & $11(8.2)$ & $35(24.3)$ & $15(20.5)$ & $31(19.4)$ & $30(40.0)$ \\
\hline Mild & $186(25.9)$ & $2(2.3)$ & $9(20.4)$ & $45(33.6)$ & $38(26.4)$ & $24(32.9)$ & $46(28.7)$ & $22(29.3)$ \\
\hline $\begin{array}{l}\text { Mild- } \\
\text { moderate }\end{array}$ & 196(27.3) & $20(22.7)$ & $1(2.3)$ & $49(36.5)$ & $42(29.1)$ & $21(28.8)$ & $46(28.7)$ & $17(22.7)$ \\
\hline Moderate & $16(2.2)$ & $2(2.3)$ & $0(0)$ & $6(4.5)$ & $2(1.4)$ & $1(1.4)$ & $5(3.1)$ & $0(0)$ \\
\hline $\begin{array}{l}\text { Moderate- } \\
\text { strong }\end{array}$ & $54(7.5)$ & $27(30.7)$ & $0(0)$ & $8(6.0)$ & $7(4.9)$ & $3(4.1)$ & $6(3.8)$ & $3(4.0)$ \\
\hline Strong & $24(3.3)$ & 12(13.6) & $0(0)$ & $2(1.5)$ & $2(1.4)$ & $0(0)$ & $8(5.0)$ & $0(0)$ \\
\hline $\begin{array}{l}\text { Mild- } \\
\text { moderate- } \\
\text { strong }\end{array}$ & $83(11.6)$ & $22(25.0)$ & $0(0)$ & $13(9.7)$ & $18(12.5)$ & $9(12.3)$ & $18(11.3)$ & $3(4.0)$ \\
\hline
\end{tabular}

Table 3. Differences between AR expression and clinicopathologic parameters in carcinoma with apocrine differentiation and metaplastic carcinoma 


\begin{tabular}{|c|c|c|c|c|c|c|c|c|c|c|c|c|}
\hline \multirow[t]{2}{*}{ parameters } & \multicolumn{3}{|c|}{$\begin{array}{l}\text { Carcinoma with apocrine } \\
\text { differentiation } \\
\text { (AR: } 10 \% \text { threshold) }\end{array}$} & \multicolumn{3}{|c|}{$\begin{array}{l}\text { Carcinoma with apocrine } \\
\text { differentiation } \\
\text { (AR: } 1 \% \text { threshold) }\end{array}$} & \multicolumn{3}{|c|}{$\begin{array}{l}\text { Metaplastic carcinoma } \\
\text { (AR:10\% threshold) }\end{array}$} & \multicolumn{3}{|c|}{$\begin{array}{l}\text { Metaplastic carcinoma } \\
\text { (AR:1\% threshold) }\end{array}$} \\
\hline & AR-pos & AR-neg & $P$ & AR-pos & AR-neg & $P$ & AR-pos & AR-neg & $P$ & AR-pos & AR-neg & $P$ \\
\hline Age(years) & & & 0.030 & & & 0.312 & & & 0.965 & & & 0.947 \\
\hline$\leq 50$ & $10(83.3)$ & $2(16.7)$ & & 11(91.7) & $1(8.3)$ & & 2(11.1) & 16(88.9) & & $4(22.2)$ & 14(77.8) & \\
\hline$>50$ & $74(97.4)$ & $2(2.6)$ & & $74(97.4)$ & $2(2.6)$ & & $3(11.5)$ & $23(88.5)$ & & $6(23.1)$ & $20(76.9)$ & \\
\hline ER & & & 0.439 & & & 0.267 & & & 0.214 & & & 0.650 \\
\hline neg & $74(96.1)$ & $3(3.9)$ & & $75(97.4)$ & $2(2.6)$ & & $4(9.8)$ & $37(90.2)$ & & $9(22.0)$ & $32(78.0)$ & \\
\hline pos & $10(90.9)$ & $1(9.1)$ & & $10(90.9)$ & $1(9.1)$ & & 1(33.3) & $2(66.7)$ & & 1(33.3) & $2(66.7)$ & \\
\hline PR & & & 0.580 & & & 0.634 & & & 0.604 & & & 0.432 \\
\hline neg & $78(95.1)$ & $4(4.9)$ & & $79(96.3)$ & $3(3.7)$ & & $5(11.9)$ & $37(88.1)$ & & $10(23.8)$ & $32(76.2)$ & \\
\hline pos & $6(100.0)$ & $0(0)$ & & $6(100.0)$ & $0(0)$ & & $0(0.0)$ & $2(100.0)$ & & $0(0)$ & $2(100.0)$ & \\
\hline HER2 & & & 0.926 & & & 0.612 & & & 0.604 & & & 0.432 \\
\hline neg & $40(95.2)$ & $2(4.8)$ & & $41(97.6)$ & $1(2.4)$ & & $5(11.9)$ & $37(88.1)$ & & $10(23.8)$ & $32(76.2)$ & \\
\hline pos & $44(95.7)$ & $2(4.3)$ & & $44(95.7)$ & $2(4.3)$ & & $0(0.0)$ & $2(100.0)$ & & $0(0.0)$ & $2(100.0)$ & \\
\hline Ki-67 index & & & 0.327 & & & 0.135 & & & 0.717 & & & 0.583 \\
\hline$<20 \%$ & $23(92.0)$ & $2(8.0)$ & & $23(92.0)$ & $2(8.0)$ & & $0(0.0)$ & $1(100.0)$ & & $0(0.0)$ & $1(100.0)$ & \\
\hline$\geq 20 \%$ & $61(96.8)$ & $2(3.2)$ & & $62(98.4)$ & $1(1.6)$ & & $5(11.6)$ & $38(88.4)$ & & $10(23.3)$ & $33(76.7)$ & \\
\hline EGFR & & & 1.000 & & & 0.734 & & & 0.518 & & & 0.877 \\
\hline neg & $21(95.5)$ & $1(4.5)$ & & $21(95.5)$ & $1(4.5)$ & & $1(20.0)$ & $4(80.0)$ & & $1(20.0)$ & $4(80.0)$ & \\
\hline pos & $63(95.5)$ & $3(4.5)$ & & $64(97.0)$ & $2(3.0)$ & & $4(10.3)$ & $35(89.7)$ & & $9(23.1)$ & $30(76.9)$ & \\
\hline
\end{tabular}

Table 4. Differences between AR expression and clinicopathologic parameters in ILC and mucinous carcinoma 


\begin{tabular}{|c|c|c|c|c|c|c|c|c|c|c|c|c|}
\hline \multirow[t]{2}{*}{ parameters } & \multicolumn{3}{|c|}{$\begin{array}{l}\text { ILC } \\
\text { (AR:10\% threshold) }\end{array}$} & \multicolumn{3}{|c|}{$\begin{array}{l}\text { ILC } \\
\text { (AR:1\% threshold) }\end{array}$} & \multicolumn{3}{|c|}{$\begin{array}{l}\text { Mucinous carcinoma } \\
\text { (AR:10\% threshold) }\end{array}$} & \multicolumn{3}{|c|}{$\begin{array}{l}\text { Mucinous carcinoma } \\
\text { (AR:1\% threshold) }\end{array}$} \\
\hline & AR-pos & AR-neg & $P$ & AR-pos & AR-neg & $P$ & AR-pos & AR-neg & $P$ & AR-pos & AR-neg & $P$ \\
\hline $\begin{array}{l}\text { Lymph } \\
\text { node }\end{array}$ & & & 0.898 & & & 0.030 & & & 0.876 & & & 0.9 \\
\hline NO & $62(79.5)$ & $16(20.5)$ & & 75(96.2) & $3(3.8)$ & & $79(66.4)$ & $40(33.6)$ & & $90(75.6)$ & $29(24.4)$ & \\
\hline N1a-3a & $44(78.6)$ & $12(21.4)$ & & $48(85.7)$ & $8(14.3)$ & & $17(68.0)$ & $8(32.0)$ & & 19(76.0) & $6(24.0)$ & \\
\hline ER & & & 0.817 & & & 0.209 & & & 0.748 & & & 0.8 \\
\hline neg & $9(81.8)$ & $2(18.2)$ & & $9(81.8)$ & $2(18.2)$ & & $3(60.0)$ & $2(40.0)$ & & $4(80.0)$ & $1(20.0)$ & \\
\hline pos & 97(78.9) & $26(21.1)$ & & $114(92.7)$ & $9(7.3)$ & & $93(66.9)$ & $46(33.1)$ & & $105(75.5)$ & $34(24.5)$ & \\
\hline PR & & & 0.850 & & & 0.162 & & & 0.033 & & & 0.7 \\
\hline neg & 21(77.8) & $6(22.2)$ & & 23(85.2) & $4(14.8)$ & & $8(44.4)$ & $10(55.6)$ & & $13(72.2)$ & $5(27.8)$ & \\
\hline pos & $85(79.4)$ & $22(20.6)$ & & $100(93.5)$ & $7(6.5)$ & & $88(69.8)$ & $38(30.2)$ & & $96(76.2)$ & $30(23.8)$ & \\
\hline HER2 & & & 0.659 & & & 0.547 & & & 0.728 & & & 0.7 \\
\hline neg & 100(78.7) & $27(21.3)$ & & 117(92.1) & 10(7.9) & & $84(67.2)$ & $41(32.8)$ & & $94(75.2)$ & $31(24.8)$ & \\
\hline pos & $6(85.7)$ & $1(14.3)$ & & $6(85.7)$ & $1(14.3)$ & & $12(63.2)$ & $7(36.8)$ & & 15(78.9) & $4(21.1)$ & \\
\hline Ki-67 index & & & 0.241 & & & 0.057 & & & 0.902 & & & 0.7 \\
\hline$<20 \%$ & 51(83.6) & $10(16.4)$ & & $59(96.7)$ & $2(3.3)$ & & $35(67.3)$ & $17(32.7)$ & & $40(76.9)$ & $12(23.1)$ & \\
\hline$\geq 20 \%$ & $55(75.3)$ & $18(24.7)$ & & $64(87.7)$ & $9(12.3)$ & & 61(66.3) & $31(33.7)$ & & $69(75.0)$ & $23(25.0)$ & \\
\hline Subtypes & & & 0.494 & & & 0.414 & & & & & & \\
\hline Classical & $13(76.5)$ & $4(23.5)$ & & 17100.0) & $0(0)$ & & & & & & & \\
\hline Variant & $85(81.0)$ & $20(19.0)$ & & $95(90.5)$ & 10(9.5) & & & & & & & \\
\hline Others & $8(66.7)$ & 4(33.3) & & 11(91.7) & $1(8.3)$ & & & & & & & \\
\hline $\begin{array}{l}\text { Nuclear } \\
\text { grading }\end{array}$ & & & & & & & & & $<0.001$ & & & 0.0 \\
\hline Low & & & & & & & $16(41.0)$ & $23(59.0)$ & & $23(59.0)$ & $16(41.0)$ & \\
\hline $\begin{array}{l}\text { Moderate- } \\
\text { High }\end{array}$ & & & & & & & $80(76.2)$ & $25(23.8)$ & & $86(81.9)$ & 19(18.1) & \\
\hline
\end{tabular}

Table 5. Differences between AR expression and clinicopathologic parameters in IPC and IMPC 


\begin{tabular}{|c|c|c|c|c|c|c|c|c|c|c|c|c|}
\hline \multirow[t]{2}{*}{ parameters } & \multicolumn{3}{|c|}{ IPC(AR:10\% threshold) } & \multicolumn{3}{|c|}{ IPC(AR:1\% threshold) } & \multicolumn{3}{|c|}{ IMPC(AR:10\% threshold) } & \multicolumn{3}{|c|}{ IMPC (AR:1\% threshold) } \\
\hline & AR-pos & AR-neg & $P$ & AR-pos & AR-neg & $P$ & AR-pos & AR-neg & $P$ & AR-pos & AR-neg & $P$ \\
\hline ER & & & 0.065 & & & 0.006 & & & 0.014 & & & 0.0 \\
\hline neg & $1(25.0)$ & $3(75.0)$ & & $1(25.0)$ & $3(75.0)$ & & $9(45.0)$ & $11(55.0)$ & & $12(60.0)$ & $8(40.0)$ & \\
\hline pos & $48(69.6)$ & $21(30.4)$ & & $57(82.6)$ & 12(17.4) & & 101(72.1) & $39(27.9)$ & & 117(83.6) & $23(16.4)$ & \\
\hline PR & & & 0.032 & & & 0.002 & & & $<0.001$ & & & 0.0 \\
\hline neg & $6(42.9)$ & $8(57.1)$ & & $7(50.0)$ & $7(50.0)$ & & 23(48.9) & $24(51.1)$ & & $34(72.3)$ & $13(27.7)$ & \\
\hline pos & 43(72.9) & $16(27.1)$ & & $51(86.4)$ & $8(13.6)$ & & $87(77.0)$ & $26(23.0)$ & & $95(84.1)$ & 18(15.9) & \\
\hline HER2 & & & 0.271 & & & 0.666 & & & 0.081 & & & $0.1^{\prime}$ \\
\hline neg & $43(65.2)$ & $23(34.8)$ & & $52(78.8)$ & 14(21.2) & & $83(72.8)$ & $31(27.2)$ & & $95(83.3)$ & 19(16.7) & \\
\hline pos & $6(85.7)$ & $1(14.3)$ & & $6(85.7)$ & $1(14.3)$ & & $27(58.7)$ & 19(41.3) & & $34(73.9)$ & $12(26.1)$ & \\
\hline $\mathrm{Ki}-67$ index & & & 0.176 & & & 0.563 & & & 0.785 & & & 0.9 \\
\hline$<20 \%$ & 11(55.0) & $9(45.0)$ & & $15(75.0)$ & $5(25.0)$ & & $20(66.7)$ & $10(33.3)$ & & $24(80.0)$ & $6(20.0)$ & \\
\hline$\geq 20 \%$ & $38(71.7)$ & $15(28.3)$ & & $43(81.1)$ & 10(18.9) & & $90(69.2)$ & $40(30.8)$ & & 105(80.8) & $25(19.2)$ & \\
\hline CK5/6 & & & 0.040 & & & 0.005 & & & 0.785 & & & 0.7 \\
\hline neg & $49(69.0)$ & $22(31.0)$ & & $58(81.7)$ & 13(18.3) & & 107(68.6) & $49(31.4)$ & & 126(80.8) & $30(19.2)$ & \\
\hline pos & $0(0.0)$ & $2(100.0)$ & & $0(0.0)$ & $2(100.0)$ & & $3(75.0)$ & $1(25.0)$ & & $3(75.0)$ & $1(25.0)$ & \\
\hline EGFR & & & 0.554 & & & 0.124 & & & 0.043 & & & 0.5 \\
\hline neg & $45(68.2)$ & 21(31.8) & & $54(81.8)$ & 12(18.2) & & $94(72.3)$ & $36(27.7)$ & & 106(81.5) & $24(18.5)$ & \\
\hline pos & $4(57.1)$ & $3(42.9)$ & & $4(57.1)$ & $3(42.9)$ & & 16(53.3) & $14(46.7)$ & & $23(76.7)$ & $7(23.3)$ & \\
\hline
\end{tabular}

\section{Figures}

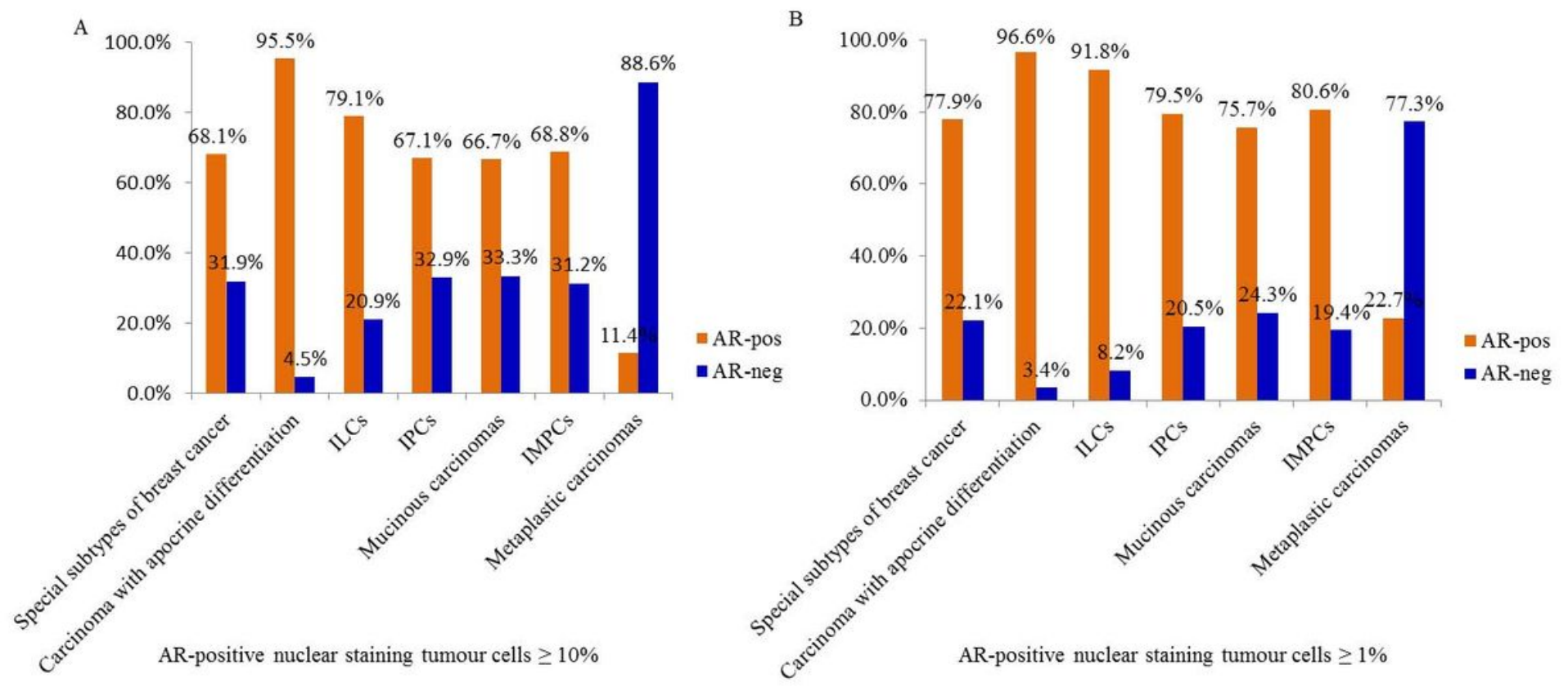

Figure 1

The positive percentage of $A R$ in different pathological subtypes of breast cancer (a $1 \%$ or $10 \%$ criterion was used). 


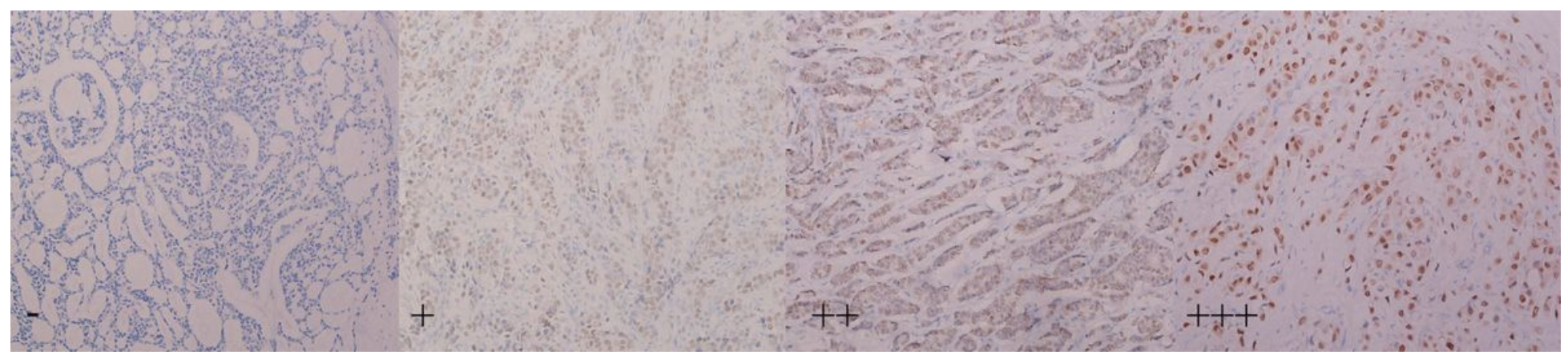

\section{Figure 2}

The negative (-) and mild (+), morderate (++), and strong (+++) immunohistochemical expression of AR in specific subtypes of breast cancer.

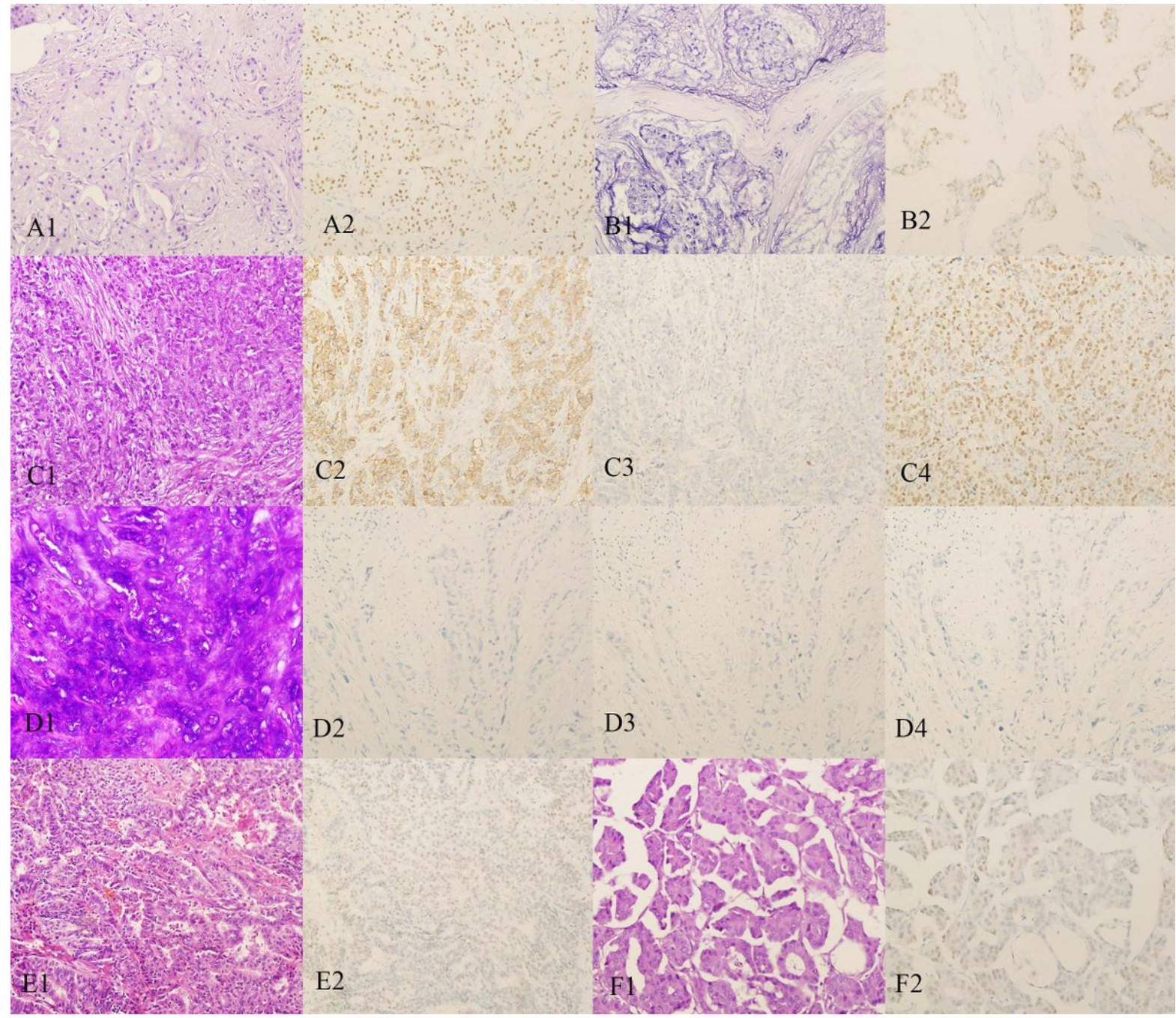

\section{Figure 3}

Carcinoma with apocrine differentiation, H\&E staining (A1), strong staining of AR (A2); Moderate-nuclear grade mucinous carcinoma, H\&E staining (B1), weak staining of AR (B2); ILC, H\&E staining (C1), positive staining of p120, with strong cytoplasm reactivity (C2), negative staining of E-CD (C3), strong staining of AR (C4); Metaplastic carcinoma, H\&E staining (D1), negative staining of ER (D2), PR(D3) and AR (D4); IPC, H\&E staining (E1), weak staining of AR (E2); IMPC, H\&E staining (F1), weak staining of AR (F2) (original magnification $\times 200)$.

\section{Supplementary Files}

This is a list of supplementary files associated with this preprint. Click to download.

- SupplementaryTable1.doc

- SupplementaryTable2.doc 